\title{
Os confins paulistas na Revolução Constitucionalista de 1932: uma análise do bandeirantismo na região da Alta Araraquarense ${ }^{1}$
}

The limits if Sao Paulo in the Constitutionalist Revolution of 1932: an analysis of bandeirantismo in the northwest.

Los confines paulistas en la Revolución Constitucionalista de 1932: un análisis del bandeirantismo en la región de Alta Araraquarense

\author{
RAQUEL DISCINI DE CAMPOS ${ }^{2}$
}

\section{Resumo}

$\mathrm{O}$ artigo discute a reconstrução sucedida nas primeiras décadas do século $\mathrm{XX}$, na região Noroeste Paulista, também conhecida como Alta Araraquarense, da mitologia em torno da figura do bandeirante. Parte das pesquisas realizadas pelo geógrafo Pierre Monbeig e pela socióloga Maria Isaura Pereira de Queiroz para tratar, por intermédio da análise da imprensa local, da ressignificação de antigas simbologias bandeirantes naquelas plagas, num período de franca expansão territorial e capitalista. Apresenta informações sobre os usos dados às instituições escolares ao longo da Revolução Constitucionalista de 1932, ápice do que se convencionou nomear como epopea bandeirante, além de discutir algumas práticas e representações dos sujeitos escolares envolvidos no conflito.

Palavras-chave: Noroeste Paulista; Bandeirantismo; História da Educação Regional;

\footnotetext{
${ }^{1}$ Artigo resultante de pesquisa financiada pelo Cnpq e pela Fapemig, a partir das discussões ocorridas no âmbito do Grupo de Pesquisas História da Educação e História Regional.

${ }^{2}$ Doutora em Educação Escolar pela Universidade Estadual Paulista Júlio de Mesquita Filho, com estágio de pós-doutorado concluído na Faculdade de Educação da Universidade de São Paulo. Professora Associada da Faculdade de Educação da Universidade Federal de Uberlândia. E-mail: raqueldiscini@uol.com.br
} 


\begin{abstract}
This article discusses the successful reconstruction in the first decades of the 20th century, in the northwest of Sao Paulo, of the mythology around the figure of the scout (bandeirante). Part of the researches carried by the geographer Pierre Monbeig and by the sociologist Maria Isaura Pereira de Queiroz to treat, through the local press, the reframing of old bandeirantes' symbologies of those regions, in a period of great territorial expansion and capitalist. It also presents information about the use given to school institutions throughout the Constitutionalist Revolution of 1932, pinnacle of what was called as bandeirante epic, discussing as well the practices of the school subjects involved in the conflict.
\end{abstract}

Keywords: Norwest of Sao Paulo; Bandeirantismo; Regional Education History.

\title{
Resumen
}

Este artículo discute la reconstrucción pasada en las primeras décadas del siglo XX, en la región Noroeste Paulista, también conocida como Alta Araraquarense, de la alegoría en torno a la figura del bandeirante. Parte de las pesquisas realizadas por el geógrafo Pierre Monbeig y por la socióloga Maria Isaura Pereira de Queiroz para abordar, por intermedio del análisis de la prensa local, la re significación de antiguas simbologías coloniales en aquellas regiones, en un periodo de libre expansión territorial y capitalista. Presenta informaciones acerca de los usos dados a las instituciones estudiantes a lo largo de la Revolución Constitucionalista de 1932, apogeo de lo que se ajustó nombrar como epopeya pionera, además de discutir algunas prácticas y representaciones de los sujetos estudiantes envueltos en el conflicto.

Palabras-clave: Noroeste Paulista; Bandeirantismo; Historia de la Educación Regional. 


\section{Pierre Monbeig, a psicologia bandeirante e o Noroeste Paulista ${ }^{3}$}

Entre os anos de 1935 e 1946, o geógrafo Pierre Monbeig fez parte do grupo de professores franceses que ministrou aulas na recém fundada Universidade de São Paulo. Ao mesmo tempo em que desempenhava suas funções na Faculdade de Filosofia, Ciências e Letras, realizava criteriosa pesquisa de campo - prática metodológica, aliás, da qual foi um dos precursores no Brasil - em busca de fontes para a tese Pioneiros e Fazendeiros de São Paulo. Defendida na Sorbonne, em 1949, foi posteriormente publicada em livro, no ano de 1952, em Paris; e em 1984, no Brasil.

Nesta obra, hoje um clássico das Ciências Humanas em geral, e dos estudos regionais paulistas, em particular, o autor buscava compreender o processo de desenvolvimento econômico pelo qual passava o Estado de São Paulo na primeira metade do século XX, discutindo as condições naturais e históricas que propiciaram o complexo incremento do capitalismo verificado na região desde meados do XIX.

Além disso, esquadrinhava a ação dos sujeitos - índios, mineiros, grandes fazendeiros, grileiros, migrantes e imigrantes, dentre outros - envolvidos no que chamou de "marcha pioneira", ou seja, a ocupação capitalista de terras anteriormente semidesertas ou habitadas pelas tribos indígenas. Contemplou a situação da "marcha" in loco nos anos de 1940, momento em que viajou pelo estado analisando o fenômeno de transformação territorial em curso: derrubada da mata nativa, criação de sítios e fazendas, surgimento de cidades e de um modo de vida rural, ou urbano, até então inexistentes.

A riqueza da obra, no que concerne à elegância da narrativa, ao levantamento meticuloso de dados e às análises inspiradas - e inspiradoras - é sobejamente reconhecida, e, diversos pesquisadores ainda hoje se debruçam sobre ela (AB'SABER, 1994; DANTAS, 2002; ANDRADE, 2011; FONSECA, 2015; SOUZA, 2015). Interessa aqui destacar, no entanto, um pequeníssimo trecho do livro (apenas quatro páginas, num montante de trezentos e noventa e uma) intitulado A psicologia "bandeirante". Nele, Monbeig discute a importância da ressignificação do mito bandeirante para avanço da "marcha", afirmando perceber uma eficácia "incontestável" na associação dos heroicos sertanistas de outrora aos modernos colonizadores do século XX. ${ }^{4}$ Nas palavras do autor

Quando se quer celebrar um fazendeiro, desbravador de matas, plantador de cidades, nenhum título melhor a deferir-lhe que o de bandeirante. Diz-se tudo de um homem, quando se diz que ele é um verdadeiro bandeirante (MONBEIG, 1984, p. 121).

\footnotetext{
${ }^{3}$ Geograficamente, a região Noroeste Paulista abrange as mesorregiões de São José do Rio Preto e Araçatuba, SP. No entanto, o recorte geográfico adotado neste trabalho está relacionado às cidades pelas quais passavam os trilhos da EFA (Estrada de Ferro Araraquara), que saía de Araraquara, passava por Catanduva, São José do Rio Preto e Mirassol, dentre outras vilas e cidades. As fontes impressas analisadas neste artigo são oriundas dessas cidades.

${ }^{4}$ Bandeirante é designação dada aos sertanistas oriundos do planalto do Piratininga que desde o século XVI se embrenharam Brasil adentro buscando enriquecimento por intermédio da descoberta de metais preciosos, do aprisionamento de índios e da destruição de quilombos, dentre outras atividades. A associação entre predicados altamente positivos e a figura do bandeirante se deu ao longo dos séculos XIX e XX (ABUD, 1986).
} 
Bem sabemos que o "dizer tudo de um homem", no caso do velho-novo bandeirante, era cobrir-lhe dos mais honrosos elogios. Eles seriam audazes, trabalhadores, aventureiros, naturalmente destinados ao comando, ícones de uma verdadeira "raça de gigantes", conforme título da famosa obra de Alfredo Ellis Jr, não por acaso publicada em 1926, período de ebulição da "marcha". 5

Andrade (2011) sinaliza que Monbeig entreviu, nesta breve e luminosa passagem da obra, a relação intrínseca existente entre representações sociais e práticas cotidianas imbricamento há tempos reconhecido nas mais variadas pesquisas desenvolvidas no campo das Ciências Humanas e, particularmente, na área da História da Educação (CHARTIER, 1991; CARVALHO; NUNES, 1993). Ao entender o poder da simbologia construída em torno do colonizador no processo de ocupação dos sertões paulistas da primeira metade do século XX, o autor demonstrou que tanto o moderno fazendeiro-pioneiro do período, quanto o pobre sitiante que pelejava para sobreviver, eram impulsionados a seguir sertão adentro por fatores não apenas econômicos, mas também simbólicos, culturais - e vice-versa. Rememorando os depoimentos que ouvira em sua jornada pelo interior paulista, o geógrafo afirmava

Não é raro ouvir dizer de um homem e de sua família que não podem ouvir o silvo da locomotiva. São os que sempre moram um pouco além da estação terminal de uma ferrovia. Quando esta prolonga os trilhos, embrenha-se o homem mais para dentro do sertão (MONBEIG, 1984, p. 122).

Ele não deixou de aquilatar os variados matizes sociais e econômicos da população envolvida na "marcha", mas indicava que todos, independentemente do berço, da etnia, da idade, da conta bancária ou da extensão e quantidade de propriedades rurais, estavam sujeitos ao que denominou de "poderosa sedução" bandeirante. Da fusão desta sedução ao "gosto pela novidade" e "atração pela sorte" - a crença generalizada nas possibilidades de rápido enriquecimento que na época circulava pelos rincões do estado - resultou a tal "psicologia" identificada por ele (MONBEIG, 1984, p. 122).

O paulista de velha estirpe acompanhava orgulhosamente a marcha para o oeste. Comprazia-se em contar como seu avô abandonara a fazenda do vale do Paraíba pela região de Campinas; em seguida seu pai abrira uma plantação na zona de Ribeirão Preto; e ele, por sua vez, continuava a desbravar a floresta na Alta Paulista ou no norte do Paraná (MONBEIG, 1984, p. 123).

Na região pelas quais passavam os trilhos da Estrada de Ferro Araraquara, Monbeig deparou-se com um dos quinhões de terra privilegiados para a realização de seus estudos. Ali, numa das últimas zonas de ocupação capitalista do estado, o geógrafo pode verificar o relevo,

\footnotetext{
${ }^{5}$ Alfredo Ellis Jr foi professor de História da Civilização Brasileira na Universidade de São Paulo a partir de 1939. Foi também diretor da Faculdade de Filosofia, Ciências e Letras, entre 1939 e 1941. Alfredo Ellis e Pierre Monbeig foram, portanto, contemporâneos na USP. Parte do acervo pessoal de ambos se encontra disponível no Instituto de Estudos Brasileiros. (http://www.ieb.usp.br/guia-ieb/detalhe/90). Acesso em 16/10/2014.
} 
os regimes de chuva e de temperatura, o solo e a vegetação, tal quais seus interesses genuinamente geográficos pelo mundo natural. Ali, o autor também constatou a importância da cafeicultura, além das plantações de algodão, da criação de gado e muares e da movelaria, dentre outras atividades econômicas desenvolvidas regionalmente, para o incremento do comércio estadual e nacional.

Naquelas terras, ainda percebeu ressonâncias originais do heterogêneo processo civilizador em curso em todo o mundo ocidental, marcado pelos avanços e recuos sociais gerados pela convivência, sempre contraditória, de pessoas e culturas diversas; pelo predomínio do discurso científico e da técnica sobre os saberes populares; pela crença no poder exercido pela educação formal sobre corpos e mentes de uma população que se adensava. Enfim, o francês observou uma mixórdia de pessoas, valores e projetos de modernização, de destruição e construção de espaços, disseminando-se a par da psicologia bandeirante, identificada como "fonte de energia" vital de todo o processo. Um verdadeiro "tumulto", na interpretação do autor.

Mas, todos esses homens jovens, povoadores de terras novas, buscavam ligar-se a uma tradição e a criar sua própria história. Talvez sentissem a necessidade de tirar dessa história, senão uma justificativa do seu tumulto, ao menos uma fonte de energia (MONBEIG, 1984, p. 124).

\section{A "psicologia bandeirante" e o "ufanismo paulista" na revolução de 1932: o caso da região noroeste ${ }^{6}$}

Se Monbeig identificou a força da "psicologia bandeirante" como um dos fatores essenciais para o desbravamento não apenas do interior do estado de São Paulo, mas, também, para a ocupação das terras hoje pertencentes a Goiás, Mato Grosso e Paraná, a socióloga Maria Isaura Pereira de Queiroz confirmou, nos anos de 1990, aquilo que já havia sido intuído pelo autor nos anos de 1930 e 1940: os desbravadores das terras no século XX se sentiam simbolicamente como os herdeiros dos sertanistas de outrora, visto que criavam novos espaços para a agricultura, empregavam técnicas modernas no trato das plantações, eram pioneiros no emprego de veículos de comunicação e lançavam-se a inéditas empreitadas. Tais fatos atestariam, segundo a ideologia arquitetada naqueles tempos, a tendência histórica dos paulistas à ousadia, à liderança e à inteligência (QUEIROZ, 1992).

Ela mapeou o surgimento, desde meados do século XIX, de um verdadeiro ufanismo paulista - aliás, também observado por Monbeig - alicerçado no desenvolvimento econômico verificado no estado. Mas aprofundou a discussão sobre a arquitetura da identidade do morador de São Paulo, demonstrando que ser paulista passou a significar, simbolicamente, ser bandeirante, ou seja, herói, aventureiro, vencedor, corajoso, irrequieto. No mais, o mesmo foi

\footnotetext{
${ }^{6}$ Para reconstruir a participação das instituições e dos sujeitos escolares daquele quinhão paulista na Revolução de 1932, procedemos à leitura dos jornais mais representativos da região. Tal representatividade se justifica tanto em função da circulação desses impressos entre as camadas médias leitoras daquele tempo-espaço; quanto em função do seu tempo de duração. São eles A Cidade, de Catanduva; A Noticia e o Diario da Araraquarense, de São José do Rio Preto. Eles estão armazenados no Museu Padre Albino, de Catanduva, e Arquivo Público Municipal, de São José do Rio Preto. Pesquisas anteriores esmiuçaram tais periódicos, e demonstraram que eles foram constitutivos da experiência social urbana que então se edificava naquelas plagas (CAMPOS, 2003, 2009).
} 
observado pioneiramente por Kátia Maria Abud (1986) e Antonio Celso Ferreira (2002), dentre outros historiadores preocupados em discutir tanto a historiografia quanto a memória paulista.

Outrossim, a pesquisadora também evidenciou o quanto as simbologias em torno dessa figura catalizadora, o bandeirante, impulsionaram a grande coesão civil existente no estado ao longo da revolução constitucionalista de 1932. Como sabemos, o episódio, também conhecido como "guerra paulista", foi um movimento armado que ocorreu em São Paulo visando à derrubada do governo de Getúlio Vargas, recém-chegado ao poder com a Revolução de 1930. Dentre os variados motivos que levaram os revoltosos a se indisporem frontalmente com Vargas, estava a demora do presidente em promulgar uma nova Constituição, conforme entendimento dos insurgentes.

Além disso, a insatisfação das elites e camadas médias locais com os interventores, nomeados pelo presidente para a administração de São Paulo, bem como o descontentamento com o rearranjo político ocorrido no poder central, com a ascensão do grupo varguista, colaborou para a deflagração do movimento, que durou três meses (CAPELATO,1981; FAUSTO,1998; BORGES, 1997). Destaca-se, portanto, que Queiroz perscrutou a construção de um imaginário regional ufanista muito característico - e que agiu fortemente como força agregadora de uma população heterogênea durante o episódio. Uma população que não teria se furtado a pegar em armas em nome de um motivo comum: a "causa paulista".

Na verdade, segundo a autora, a revolução de 1932 foi momento ímpar para que a simbologia em torno dos paulistas/bandeirantes atingisse o auge de sua força coercitiva, ultrapassando círculos intelectuais elitizados e chegasse até grande parte da população. Segundo a socióloga, "todos os que se esmeravam em servir o movimento deflagrado atestavam que eram descendentes, senão na origem, pelo menos no espírito e nas virtudes dos antigos sertanistas" (QUEIROZ, 1992, p. 85).

Como sabemos, os meios de comunicação de massa foram largamente utilizados naquele episódio: cartazes que ainda hoje nos parecem familiares e que compõem a mítica em torno da figura do paulista bandeirante eram distribuídos em lugares estratégicos. Programas de rádio, bem como documentários produzidos in loco, e que exibiam o dia-a-dia dos combatentes nas trincheiras, eram diuturnamente veiculados nos cinemas. Fotografias das mobilizações das massas urbanas eram estampadas em álbuns, revistas e, principalmente, nos jornais diários que circulavam em todo o Estado de São Paulo - mas também além-fronteiras.

No Noroeste Paulista não foi diferente. Particularmente as cidades de Catanduva e São José do Rio Preto, cidades polo da região da ferrovia Araraquarense, tiveram os seus impressos quase que inteiramente tomados pela "causa paulista", "guerra paulista", "alma paulista"; "arrancada gloriosa" ou "extraordinária epopea cívica", conforme variações fraseológicas que versavam sobre um mesmo assunto: o prestígio daquele povo e daquele rincão. Em Catanduva, por exemplo, local cujos moradores se envolveram ativamente na revolução, o impresso da cidade diagnosticava, no dia da deflagração do movimento que

O povo bandeirante, honrando a tradição e a memória de seus maiores, tendo acima de tudo o bem geral e a grandeza da pátria, levanta-se num arrojado gesto de profunda brasilidade, de sadio patriotismo (A Cidade, 09/07/1932). 
Já São José do Rio Preto, cujos habitantes também tomaram parte ativa na conflagração, estampava em primeira página do seu jornal, A Noticia, um dos mais lidos no período, as impressões emitidas pelo professor e jornalista Leonardo Gomes sobre os combatentes. Ele, que era também o diretor do jornal, escrevia diretamente de um dos campos de batalha, no momento da declaração de guerra: "E ninguém se queixa! E todos marcham para o campo do dever conscientes das suas máximas responsabilidades de paulistas e de brasileiros!" (A Noticia, 18/07/1932).

Naquele contexto, disseminou-se por aquelas plagas a crença de que os revoltosos estariam novamente vivendo uma epopeia envolvendo grandes lutas e sacrifícios pessoais, em nome de todo o país. Essa espécie de fé num destino inexorável e glorioso se tornou recorrente ao longo da curta revolução, e também nos anos subsequentes a ela, quando se construíram narrativas vencedoras e moralizadoras sobre o conflito - de onde os paulistas, aliás, efetivamente saíram derrotados pelas tropas aliadas ao governo central.

Todavia, importa destacar que ainda hoje tais narrativas são constitutivas do panteão cívico paulista. ${ }^{7}$ Assim observamos, por exemplo, nos excertos reproduzidos a seguir, retirados de impressos de São José do Rio Preto e Catanduva, respectivamente, e que demonstram a construção da memória sobre o movimento ao longo das décadas.

A imagem do suplemento especial d' A Noticia, publicado em julho de 1936, é icônica. Bandeirante e revolucionário frente à frente, tendo ao fundo a bandeira do Estado. O combatente presta continência respeitosa ao bandeirante - e à sua própria história. Está honrando a "São Paulo de sempre!", traduzida na primeira frase do texto destacado em vermelho, que anuncia: "São Paulo, posto em pé, ouviu a voz que lhe vinha do fundo dos séculos, falando de sacríficos e de gloria. Era a voz da Bandeira". Entre o herói do passado e o daquele presente da década de 1930, o brasão do Estado, instituído por ocasião da própria Revolução. Louros, pés de café, espada de aço e o lema "Pro Brasilia Fiant Eximia" denotam a clara certeza de que o estado de São Paulo era o esteio da nação: "pelo Brasil façam-se grandes coisas".

Outros símbolos da pujança e da liderança paulista, além dos ramos de café que se repetem dentro e fora do brasão, também aparecem na página do impresso: iluminação urbana, arranha-céus e fábricas, cujas chaminés emitem uma fumaça que, pelas mãos do artista, se transformam em imagem de nobilíssima história. A data da deflagração do conflito, inscrita em numeração romana no chapéu do combatente desenhado em primeiro plano, reforça o tom épico, heroico e atemporal dos grandes feitos dos modernos heróis do interior paulista.

\footnotetext{
${ }^{7}$ Podemos citar como memória presente do conflito ainda hoje o fato de que o 9 de julho é o grande feriado do estado. Os monumentos em honra aos combatentes se espalham por todo o território. Além disso, as praças, ruas e avenidas nomeadas em homenagem às datas icônicas (23 de maio, 9 de julho) e aos mártires e heróis (Martins, Miragaia, Dráusio e Camargo, Voluntários de 1932 etc) povoam as cidades da região.
} 
Figura 1: A Noticia, 9 de julho de 1936.

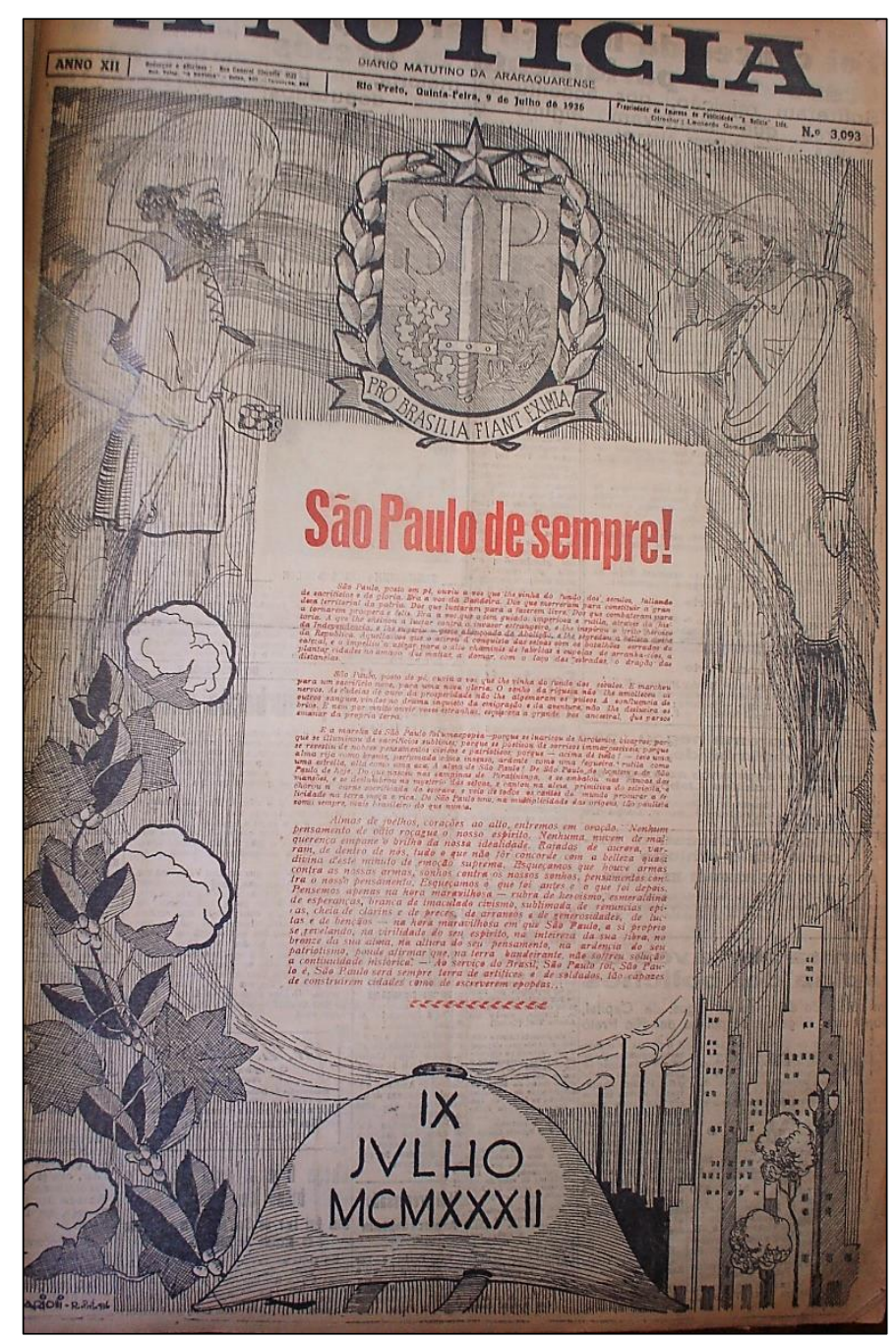

O mesmo tom pode ser observado nos anos e impressos subsequentes: 1937; 1949 e 1963, como aqueles reproduzidos a seguir. Uma tradição de narrativa mítica se instaura, possibilitando que qualquer paulista, mesmo não tendo combatido diretamente nas trincheiras, fosse capaz de sentir, "pela intuição", o calor da "guerra", conforme diziam os arautos da glória da região. Pura memória, naquilo que ela tem de mais seletivo, criativo e hierarquizante em relação aos fatos concretamente vividos - ou idealmente projetados pela imaginação, conforme bem ensinou Le Goff (1994).

\section{BRASIL!}

Sonho perene da alma paulista, que acendeu, no planaldo de Piratininga, a fogueira alumiadora dos rumos da pátria. Sonho perene do coração bandeirante, que lidou em todos os quadrantes da Terra de Santa Cruz, para que ella fosse grande e fosse bela.

Brasil! 
Nome que no dia de hoje é rezado por todos os corações paulistas. Porque pelo Brasil é que todos nós lutamos. Pelo Brasil é que os nossos irmãos morreram, e as nossas mães choraram.

Brasil! (Folha de Rio Preto, 11 de julho de 1937).

Quanta coisa nos accode á mente ao lembrarmos a revolução paulista! Quanta tenacidade, quanto heroísmo e, sobretudo, que estoica capacidade de sacrifício a do povo bandeirante! A juventude dos campos, das cidades e das escolas trocaram os seus misteres pela lucta nos campos abertos, varridos pela metralha ceifadora. A mocidade paulista traçou com a ponta das bayonetas reverberantes a Historia da Patria, a sua própria Historia, enquanto na retaguarda das linhas de combate a mulher paulista realisava também a sua epopea (A Cidade, 30 de julho de 1937).

O dia de hoje, para os de Rio Preto, é principalmente de evocação e de saudade. As nossas comemorações vão fazer-se ao pé da Casa dos Mortos, junto ao tumulo dos que deram a sua vida Á Pátria, em nome de S. Paulo (Diario da Araraquarense, 9 de julho de 1949).

Disse um velho paulista, desses raros, de barba e bigode ralos, numa hora bem amarga - PARA O PAULISTA DE BRIO E HONRA, 9 DE JULHO DE 32 É SIMBOLO IMORTAL"!

Honra e glória à brava gente bandeirante!

AH! - SÃO PAULO! - SÃO PAULO! - SÃO PAULO!... (A Cidade, 1963).

É fato que nos meses do conflito, e muito tempo depois, ainda repetia-se cotidianamente nos jornais da região a icônica assertiva: "São Paulo, o único estado do Brasil que já é Brasil" (A Noticia, 1937), revelando outra identificação muito recorrente no período - aquela que coligava o estado à "locomotiva da nação". É manifesto, ainda, o movimento de super valorização da figura do bandeirante na revolução de 1932 nos impressos do noroeste, uma região que, como já observado, foi território privilegiado para os estudos de Monbeig, pois era palco onde se desenrolava a marcha; mas também zona especial para a apreensão da ressignificação das simbologias paulistas em 1932, pois se transformou em espaço militar estratégico em função da situação fronteiriça com Minas Gerais e Mato Grosso, à época aliados do governo central. Ambos os fatores que potencializaram a verdadeira sacralização da figura do bandeirante ocorrida naquelas plagas.

A característica sabida do bandeirismo, irradiado de São Paulo, foi, como todo mundo sabe, uma como que continuação atávica, tradicional, histórica, fatal, do impulso de expansão da fé e do império, que gerou a epopéa lusa dos séculos XIV-XV. Sem que houvessem rompido os elos 
que prendem o nosso século aos primeiros da nossa vida nacional, sabe o paulista, mais uma vez, reunindo-se na maior, na mais descomunal das bandeiras, investir de novo contra todos os inimigos e defrontar-se contra todos os perigos, para levar a todo o país a idea vigorosa de uma nacionalidade gerada aqui e daqui, extendida em nosso território inteiro (A Noticia, 1932).

O sentimento, ou, melhor dizendo, o auto reconhecimento entre a figura do paulista e a do bandeirante ultrapassou largamente as meras identificações entre residente e território, transformando-se numa das forças ideológicas mais intensas e perenes atreladas à imagem dos nascidos em São Paulo - e particularmente entre os habitantes do noroeste. Mas não apenas entre eles. Também os que se tornaram paulistas, quer fossem migrantes e imigrantes, passaram a se reconhecer como bandeirantes. ${ }^{8}$

Figura 2: A legenda que acompanha a foto, publicada em encarte especial do jornal Diario da Araraquarense, por ocasião das comemorações da Revolução Constitucionalista ocorridas em 1935, informa: "Quatro phisionomias conhecidas: Justino Moreyra, Fuad Scaff, Ulderico T. Piza e Sebastião Azevedo Barreto, posando para a nossa objetiva em 4-8-932 (Diário da Araraquarense, 1935).

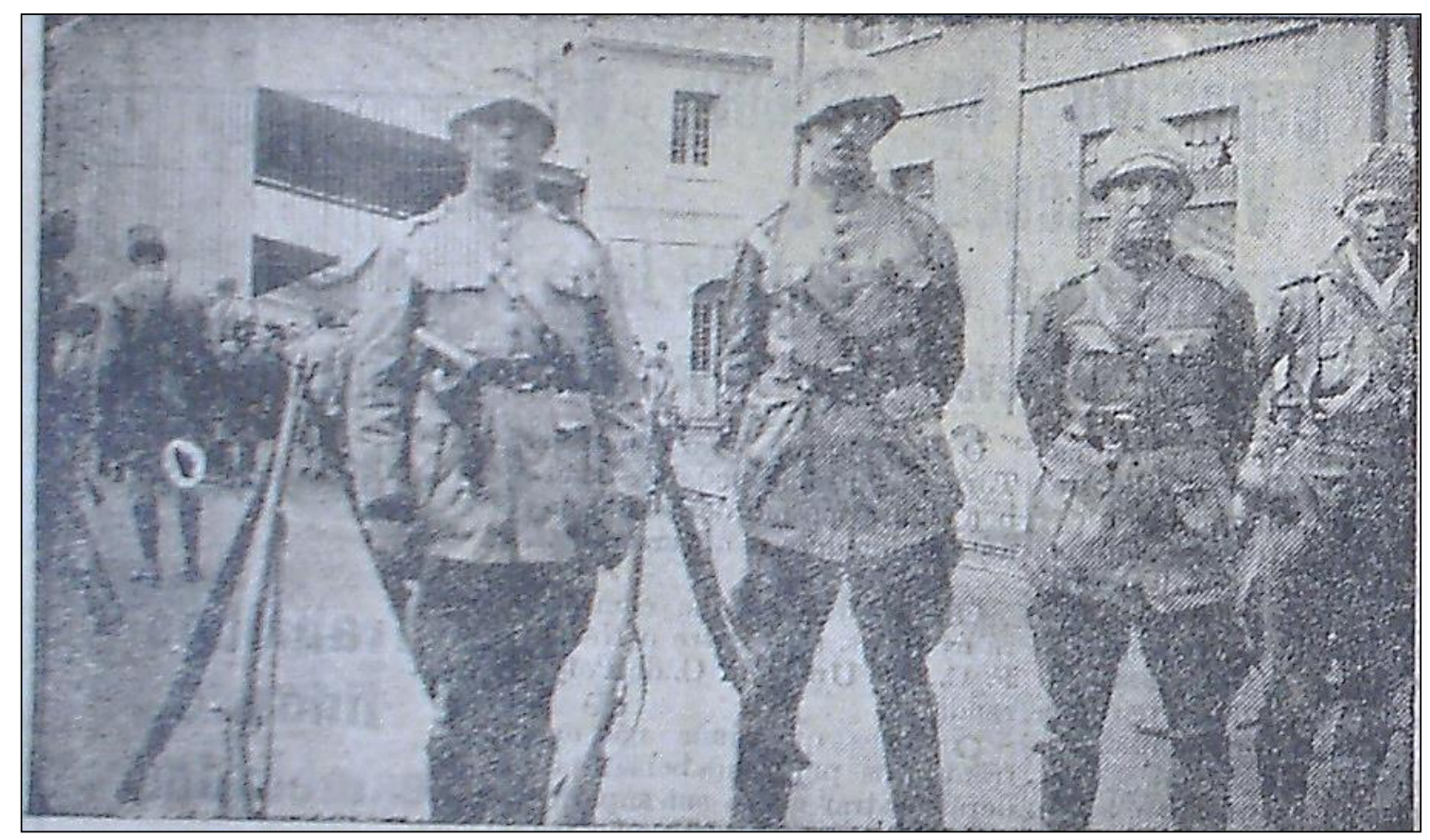

Para os combatentes e voluntários locais - mais ou menos 600 homens - foram dispensados não apenas o treinamento (pouco) adequado, mas os donativos, as preces, os poemas, o ouro, os remédios, os churrascos realizados com bois doados por fazendeiros, os capacetes de aço forjados pelos ferreiros locais, os binóculos e a munição que, porventura, um

\footnotetext{
${ }^{8}$ É importante destacar que Queiroz demonstra que a construção da simbologia bandeirante não se deu apenas em torno de coesões sociais, pelo contrário. "Bandeirantes" ou "paulistas" de velha estirpe se destacavam tradicionalmente dos demais: os novos ou não tão velhos assim (QUEIROZ, 1990).
} 
ou outro morador oferecia para a "causa". Assim verificamos nas listas de doadores publicadas pela imprensa regional. Delas, destacamos alguns nomes e suas contribuições, ressaltando que somente um doador não é identificado nominalmente, ou tem registro de ascendência destacado - justamente aquele que só pode contribuir com um alfinete. Observe-se, entretanto, a sagração deste indivíduo sem nome, identificado como "um brasileiro" - ele também, afinal, um bandeirante.

Relação dos donativos entregues ao Banco Commercial do Estado de S. Paulo, agencia de Rio Preto:

Meninos Arthur e Milton, filhos do Sr. Paulo Marcos dos Santos: um anel, duas pulseiras e uma corrente, com 6,30grms e 2 moedas de prata. Meninas Vera e Gessy Fava: um broche e um anel com 5,90 grms; 3 moedas de prata italianas e 6 moedas de cobre.

Sr. Jose Mussi e senhora e filhos Ulysses e Rubens: duas correntes, um prendedor de gravata, uma cruz e uma caixa de relógio pulseira, com 31 grms; um relógio de ouro "Invicta".

Um brasileiro: um alfinete com 4 grms (A Noticia, 21/08/1932).

Importante salientar que a mesma publicidade altamente euforizada dada aos heróis do noroeste paulista - e a todos os cidadãos da região que colaboravam de uma maneira ou de outra com a revolução - dia após dia nos impressos, também era destinada, só que numa abordagem oposta, àqueles que haviam se alistado como voluntários no calor da hora e que, no entanto, não compareciam para empunhar as armas de fato. Eles também eram nomeados em primeira página. Entre chamamentos públicos, multiplicavam-se as notas de censura e perplexidade diante do silenciamento de alguns.

Numerosos rapazes que se inscreveram como voluntários, nesta cidade, não tem podido, em virtude do seu horário de trabalho, comparecer aos exercícios e aulas de instrucção militar que estão sendo dadas diariamente no quartel do Regimento de Infantaria de Rio Preto, em funccionamento no edifico do 1 Grupo Escolar. Essa deve ser a razão única para o não comparecimento, que se tem verificado de muitos delles (A Noticia, 27/07/1932).

A esses antiexemplos da "arrancada paulista" restava, afinal, o desprezo dos combatentes, bem como o de toda uma coletividade envolvida na defesa da "guerra". Chamados habilmente de covardes e egoístas, estes só poderiam envergonhar a comunidade, muito diferentemente dos verdadeiros descendentes dos Tavares, Camargos, Andrades etc. ${ }^{9}$

\footnotetext{
${ }^{9}$ O professor Enoch de Morais e Castro, por exemplo, diretor da Escola de Comércio D. Pedro II, criou o Centro Cívico Mineiro, de orientação contra-revolucionária. Após o término da revolução, teve que se mudar da cidade de Rio Preto, mesmo estando do lado vencedor, em função da inimizade geral (ARANTES, 2001).
} 
Mas, nesta campanha redemptora, quando muitos chefes de família aqui em nossa cidade um bom número delles - se afastam de esposas e de filhos menores para correrem à lucta - que motivo decoroso poderão invocar, para fugir ao dever, homens e rapazes cujas famílias não dependem essencialmente delles? (...) Se há quem possa viver assim, não será, por certo, nenhum paulista, nenhum brasileiro que se preze de o ser (A Noticia, 02/08/1932).

Assim sendo, destacamos o esforço dos impressos daquela região tanto na construção de uma memória sobre o conflito após o seu término; quanto na arregimentação de voluntários para a revolução ao longo do acontecimento. Eles exerceram papel importante na mobilização da população em geral nas trincheiras, reais ou simbólicas, da revolução constitucionalista de 1932, palco da nova saga dos bandeirantes. Eram os jornais, juntamente com outras instituições locais, tais como a escola, a Igreja Católica, os clubes e agremiações, que contribuíam para a ampla arquitetura dos "mártires" mortos em combate, e das centenas de "heróis", "cidadãos de bem", "verdadeiros paulistas" que lutavam pela redemocratização do Brasil. Dos bandeirantes da região, por fim. ${ }^{10}$

\section{As escolas, a revolução o engrandecimento do mito bandeirante}

Sem dúvida que a escola paulista, por intermédio da ação de seus sujeitos, colaborou decisivamente para a arquitetura da mítica em torno do bandeirante, quer seja por intermédio dos currículos e livros oficiais, quer seja por meio das práticas celebrativas cotidianas desenvolvidas tanto dentro quanto fora da instituição. Bem sabemos a força que os materiais didáticos adotados, as músicas e poesias apresentadas nos rituais cívicos, os monumentos erigidos em praça pública e tantas outras ações e representações rotineiras tiveram na construção de tal simbologia (ABUD, 1986; CERRI, 1998; FERREIRA, 2002). Conforme observado no excerto abaixo, o próprio Monbeig foi muito sensível na apreensão de tal fenômeno da cultura escolar regional.

Num país cujo passado é curto, fica-se apaixonadamente preso ao que ele pode ter de prestigioso. Sendo um dos mais assombrosos da jovem história brasileira, o episódio das bandeiras impressiona muito as crianças. Ao aprender a ler, aprende o brasileiro a história dos bandeirantes: Borba Gato, Fernão Dias Pais, são os heróis nacionais, cuja recordação se mantém muito viva (...) A intrepidez desses pioneiros de extensa linhagem, sua ousadia de aventurar-se tão longe, com tão escassos meios, no imenso Brasil, exercem forte atrativo sobre as crianças e os adolescentes (...) (MONBEIG, 1984, p. 121).

\footnotetext{
10 Segundo relato do historiador Lelé Arantes, além da formação da Cruzada Gymnasial, da Comissão Municipal MMDC, da Casa do Soldado e da Federação dos Voluntários de Rio Preto, organizações que visavam dar apoio direto ou indireto à revolução, formou-se também naquela cidade a temida Coluna da Morte, integrada por matadores de aluguel famosos na região, como Aníbal Vieira, Ferraz Negrão, Lino Catarino e seu irmão Ubirajara (ARANTES, 2001).
} 
Se a revolução constitucionalista de 1932 foi o ápice da identificação entre o paulista e o bandeirante; e se tal identificação se deu de forma muito intensa via cultura escolar, o que dizer das instituições e sujeitos escolares da região noroeste, palco privilegiado do conflito?

São os impressos locais que nos dão pistas sobre a centralidade ocupada pelos grupos e ginásios da região, bem como por seus professores, diretores e alunos na deflagração. $\mathrm{Na}$ semana seguinte à declaração de guerra, A Noticia estampava em primeira página o aviso: "Estão suspensas até segunda ordem as aulas dos estabelecimentos públicos do Estado - os respectivos prédios ficam a disposição das autoridades" (A Noticia, 14/07/1932). De fato, o $1^{\circ}$ Grupo escolar de Rio Preto, bem como parte dos ginásios e grupos das demais cidades da região, se transformou em quartel general dos constitucionalistas, enquanto durou a revolução, e das tropas federais, após a derrota.

Figura 3: Treinamento dos voluntários de Rio Preto no pátio do $1^{\circ}$ Grupo Escolar, atual Cardeal Leme (Fonte: Diário da Região, 10/07/2005). Vemos uma única criança à frente do batalhão, fotografado em perspectiva diagonal. A construção do grupo é modesta, se comparada aos templos de civilização perscrutados por Souza (2008). Mas a intenção do fotógrafo parece ser a de criar monumentalidade, tanto arquitetônica quanto humana.

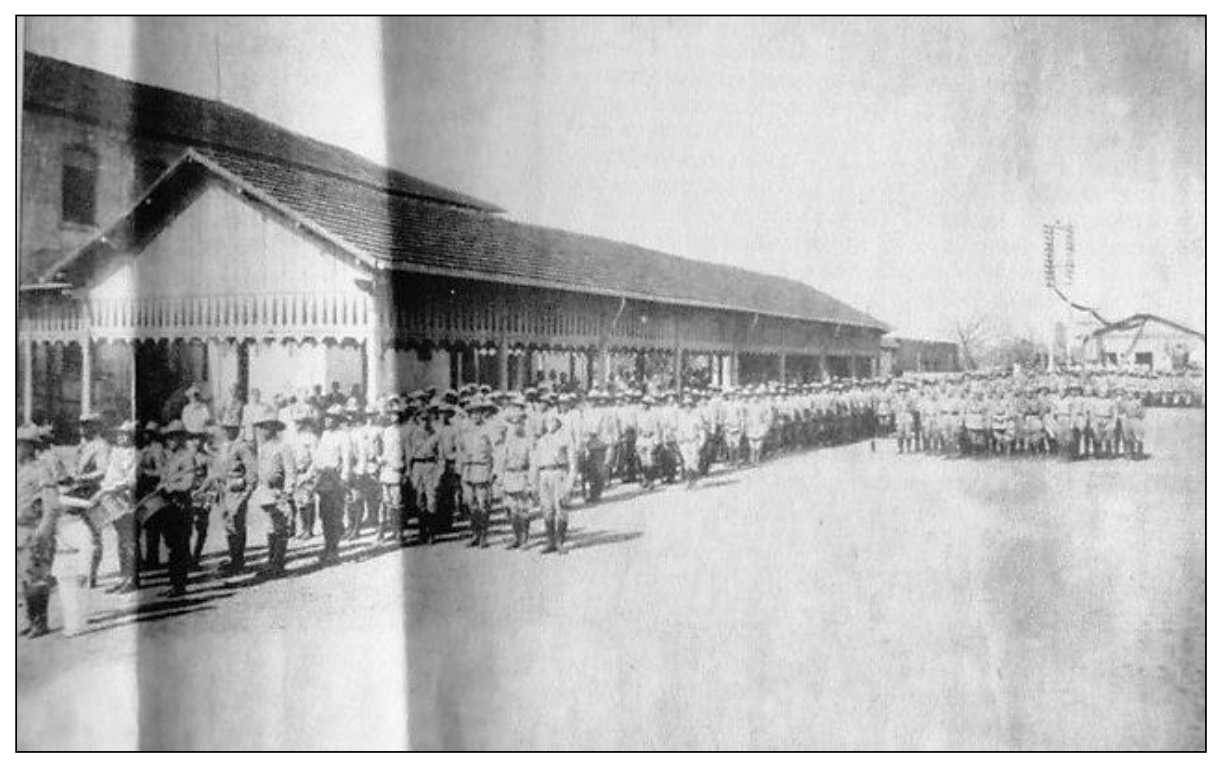

O caso do $1^{\circ}$ Grupo de Rio Preto, um dos símbolos mais importantes dos ideais de progresso e civilidade das elites e camadas médias regionais, é emblemático desses novos usos que passaram a ser dados aos espaços escolares no ano de 1932. Em nome dos esforços de guerra, as aulas foram definitivamente suspensas para o treinamento dos voluntários - e só voltaram a ser ministradas novamente no prédio em 1933. Pela "causa paulista", batalhões infantis foram criados para dar ânimo às tropas. Para perpetuação da "glória bandeirante", as crianças declamavam poemas nacionalistas nos portões das escolas, visando à audiência e o encorajamento tanto dos soldados acantonados quanto dos cidadãos em geral. Aliás, o mesmo movimento ocorria em outros estabelecimentos escolares do estado, tal como podemos observar. 
Numa reunião havida no Gymnasio do Estado entre directores de gymnasios, ficou decidida a creação da Cruzada Gymnasial Paulista, da qual farão parte gymnasianos de menor edade, os quaes serão approveitados em diversos serviços de assistência, na capital e nas cidades do interior onde o mesmo serviço seja organizado (A Noticia, 22/07/1932).

Os professores dos grupos, ginásios e escolas normais, por sua vez, organizavam atividades como bailes, festas e almoços beneficentes, visando arrecadar fundos para o financiamento das tropas. Como demonstrou a historiografia dedicada ao tema, rapidamente os revoltosos perceberam que não possuíam a mínima infraestrutura para enfrentar uma guerra. Faltavam armamentos, uniformes, soldados e comida, dentre outros itens elementares para a continuidade da insurreição (CAPELATTO, 1981; FAUSTO, 1998). Daí a ampla participação dos professores na arrecadação de donativos.

Realiza-se na próxima quarta feira, conforme temos noticiado, no Cine Theatro Capitolio, desta cidade, a festa promovida pelos professores do Grupo Escolar, em beneficio da Cruzada de Capacetes de Aço. Dada a animação reinante e o empenho em que se acham os promotores da festa é de se esperar que a mesma se revista de extraordinário brilhantismo (A Noticia, 21/08/1932).

Mas era justamente na frente ideológica do conflito que alunos e professores da região combatiam. Era na trincheira cultural, por intermédio da assistência de discursos inflamados, declamação de poemas, entonação de hinos patrióticos e organização de palestras cívicas, dentre outras atividades, que os sujeitos escolares se faziam mais presentes no ambiente de guerra de 1932.

As 10 horas houve sessão na Escola Normal, à qual compareceram os professores e alumnos, fazendo-se ouvir o professor Waldo de Abreu, que pronunciou eloquiente discurso. As 14 horas realizou-se a sessão no Teatro São Pedro, patrocinada pelo Gremio. Deante de uma assistência numerosa, discursou o prof. Osmar Conceição, salientando o valor de São Paulo na formação do Brasil de hoje. Fallaram também a senhorita Antonietta de Camargo, oradora do Gremio e o Sr. Candido Brasil Estrella. As senhoritas Daria Moreira, Nair Moreira e Iria C. Souza, recitaram bellas poesias de auctores paulistas (A Noticia, 27/07/1932) 
Figura 3: Soldados, voluntários, autoridades, mulheres e crianças posam em frente ao Instituto Rio Branco -atual FATEC- de Catanduva, instituição que foi transformada em quartel-general na revolução de 1932 (Fonte: Museu Padre Albino, Catanduva, SP).

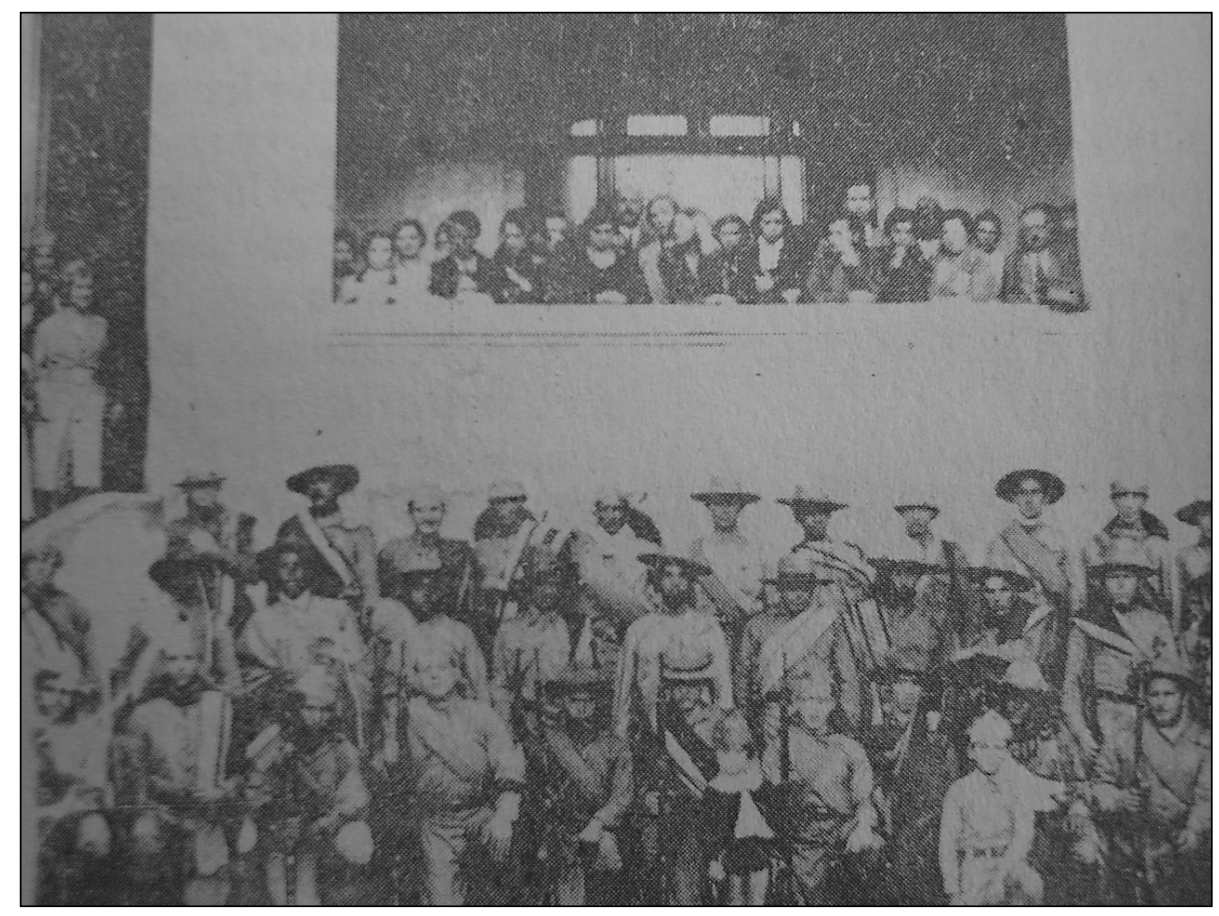

É necessário destacar que o fenômeno da transformação das escolas em quartéis, e da criação dos famosos batalhões infantis, ocorrido em 1932 - fatos que podem causar estranhamento aos olhos contemporâneos - foram potencializados por uma tradição característica das escolas primárias paulistas: a militarização da infância (SOUZA, 1998; 2000). A autora explicou como as práticas de natureza cívico-militar, destacadamente o escotismo, estiveram presentes nos ambientes escolares do estado desde as suas origens, colaborando fortemente para a implementação do projeto republicano em voga na virada dos séculos XIX/XX.

Na verdade, ela demonstrou que desde a primeira reforma republicana da instrução pública, realizada em 1892, a disciplina Ginástica e Exercícios Militares foi introduzida no currículo oficial. Salientou que diante do desconhecimento dos docentes para ministrar tal disciplina, na prática ela era desenvolvida por soldados reformados do Exército, sendo que um dos livros pelo qual professores e soldados se orientavam para o preparo das aulas era Instruções ao Exército Brasileiro.

A partir da constatação de que a militarização da infância nasceu, em São Paulo, ao par do processo de escolarização das crianças, não é de se estranhar a formação dos batalhões infantis desde os primeiros anos de existência dos grupos. Eles foram regulamentados oficialmente em 1904, e funcionaram como pequenas corporações militares desde então: os alunos recebiam treinamento específico, andavam fardados, portavam apetrechos que imitavam armas etc. Tudo consoante ao espírito patriótico da época, que entendia que tais práticas escolares favoreceriam o desenvolvimento de corpos e mentes disciplinadas, além de contribuírem para a construção de cidadãos eugênicos, moralizados, nacionalistas etc. 
Souza comprovou, além disso, que mesmo após o ocaso dos batalhões infantis, ocorrido após a Primeira Guerra Mundial, a prática do escotismo, bastante difundida nos grupos nos anos de 1910 e 1920, conservou as aprendizagens militares muito vivas dentro das escolas, pois estas eram vistas pelos educadores de então como propícias para a inculcação dos valores patrióticos em voga. Nesse sentido, a autora afirma que "foi essa associação entre educação cívica e nacionalismo que facultou o entusiasmo pelo escotismo e a sua implantação em massa na instrução pública paulista, fato de grande relevância para se compreender o surgimento de determinadas práticas escolares e suas dimensões simbólicas" (SOUZA, 2000). Salienta-se, por isso, que os batalhões infantis que emergiram no bojo da revolução de 1932 no noroeste paulista dialogavam com uma cultura escolar há tempos existente em todo o estado de São Paulo, desde os primeiros tempos da história dos grupos.

Daí a naturalidade, o entusiasmo e o estímulo à prática depreendidos do relato da professora rio-pretense ao observar os modestos, porém atuantes, batalhões infantis do interior do estado, particularmente os de Rio Preto. "Se não tens coragem, fica, nós iremos!", bradavam as crianças pelas ruas da cidade naquele conturbado período, estimulados fortemente pelo exemplo de seus professores.

O enthusiasmo do nosso movimento revolucionário não podia deixar de repercutir nos meninos de hoje, soldados paulistas de amanhã, tão vibrante e eloquente como nos velhos e moços de hoje.

Desde os anciãos de cabelos de neve, até as creanças que mal balbuciam, tudo é um só dizer, um só enthusiasmo: "Tudo pela causa sagrada de São Paulo".

Entre as manifestações que mais me commovem, merece especial menção o "Batalhão Infantill". Desfilando garbosas pelas ruas, saem enfileiradas innumeras creanças. Na frente ostentam as bandeiras nacional e paulista.

Obedecendo disciplinadamente à voz do commandante, percorrem as ruas principaes, entoando hymnos patrióticos, principalmente o dos soldados...Passos acertados, ao som dos tambores que são latas velhas, empunham os seus fuzis de madeira, transportam cartazes com dizeres significativos, taes como "Vencer ou morrer", "Tudo por São Paulo, "Se não tens coragem, fica, nós iremos!", "Alista-te".

Mas se o batalhão do interior é modesto, o da capital é perfeito. Conta milhares de creanças divididas em outros corpos. Alem da farda caprichosamente feita, o exercito com o estado maior graduado, possuem elles metralhadorazinhas, canhões, aeroplanos, tudo minúsculo, como os soldados. Figuram o corpo de saúde com as enfermeirazinhas e as ambulâncias pequenitas e, ainda, o batalhão de engenheiros.

Tudo admirável, commovente, arrebatador. Quer nos imponentes batalhões da capital, quer nos modestos exércitos do interior, reina em todos a mesma alegria e enthusiasmo, incentivando os homens que ainda não tiveram a boa vontade de trabalhar pela causa sagrada da lei. Estes soldadinhos com a sua boa disposição, visando sempre o seu Estado e sua Patria, dão-nos um bello exemplo de patriotismo. E os paulistas sentem a impressão de amparo e o perpetuar do seu valor, nessa nova geração que, educada no civismo, baseada na lei, ostentará, sempre gloriosa, a bandeira nacional (Rosa Thereza Vallini, do Collegio Santo André de Rio Preto. A Noticia, 1932) 
Assim, destacamos que os batalhões infantis contribuíam com a espetacularização da Revolução de 1932 na região Noroeste do Estado de São Paulo e, mais importante, com a ressignificação dos símbolos bandeirantes ocorridos no período, especialmente com a ideia da existência de uma espécie de coragem intrínseca ao povo paulista. No mais, observamos, no depoimento da professora, ora eufórico, ora edulcorante, a celebração das categorias profissionais presentes nos batalhões (engenheiros, enfermeiros etc). Notamos, também, a confirmação das antigas hierarquias de gênero, historicamente construídas e tão em voga no período - meninos empunham armas e tocam tambor, meninas formam o batalhão das cuidadoras. Lembramos, também, a simbolização da existência de um único corpo cívico naquelas plagas, formado por "anciãos de cabelos de neve" e "creanças que mal balbuciam". Novos e velhos bandeirantes que não se furtavam em cumprir uma espécie de missão cívica atávica.

Podemos entender, finalmente, que as escolas da região tiveram, quer seja por intermédio do ensino oficial, da cultura escolar produzida, e, principalmente pela intervenção de seus sujeitos no espaço público, papel destacado tanto na construção quanto na ressignificação ocorrida nos símbolos paulistas, em especial sobre aqueles ligados ao bandeirantismo, colaborando decisivamente para a edificação de um imaginário presente ainda hoje entre parcelas significativas da cultura local.

\section{Referências}

AB'SABER, A. Pierre Monbeig: a herança intelectual de um geógrafo. Revista Estudos Avançados, vol. 08, n. 22, p. 221- 232, 1994. https://doi.org/10.1590/S0103-40141994000300024

ABUD, K.M. O sangue intimorato e as nobilíssimas tradições: a construção de um símbolo paulista, o bandeirante. Tese de doutoramento. FFLCH - USP, 1986.

ANDRADE, J.C. Pierre Monbeig. Um francês diante da geografia do movimento: um estudo sobre a obra Pioneiros e Fazendeiros do Estado de São Paulo. Revista IEB. n. 52, p. 43-68, 2011.

ARANTES, L. Dicionário Rio-pretense. São José do Rio Preto: Casa do Livro, 2001.

BORGES, V. P. Memória paulista. São Paulo: Edusp, 1997.

CAMPOS, R. D. A “princesa do sertão na modernidade republicana: urbanidade e educação na Rio Preto dos anos de 1920. SP: Annablume, 2003.

CAMPOS, R. D. Mulheres e crianças na imprensa paulista: educação e história. SP: Unesp, 2009. https://doi.org/10.7476/9788539304424

CAPELATO, M. H. O movimento de 1932: a causa paulista. São Paulo: Brasiliense, 1981.

CARVALHO, M.M.C; NUNES, C. Historiografia da Educação e fontes. Cadernos ANPEd, no 5, p. 7-64, 1993.

CERRI, L.F. Non ducor, duco. A ideologia da paulistanidade e a escola. Revista Brasileira de História, vol. 18, n. 23, p.115-136, 1998. https://doi.org/10.1590/S0102-01881998000200007 
CHARTIER, Roger. O mundo como representação. Estudos Avançados, São Paulo, v. 5, n. 11, p. 173-191. 1991. https://doi.org/10.1590/S0103-40141991000100010

DANTAS, A. Monbeig, paisagem e geografia estigmática. Mercator - Revista de Geografia da UFC. Fortaleza, n. 02, p. 71-78, 2002.

FAUSTO, B. História do Brasil. São Paulo: Edusp, 1998.

FERREIRA, A.C. A epopéia bandeirante: letrados, instituições, invenção histórica (18701940). São Paulo: Unesp, 2002. https://doi.org/10.7476/9788539303038.

FONSECA, S. C. Ribeirão Preto e a chegada da assistência institucional à infância ao Oeste Novo. Cadernos de História da Educação. vol. 14, n. 2, p. 461-481, 2015.

LE GOFF, J. História e Memória. Campinas: Unicamp, 1994.

MONBEIG, P. Pioneiros e Fazendeiros de São Paulo. São Paulo: Hucitec/Polis, 1984.

QUEIROZ, M.I.P. Ufanismo paulista: vicissitudes de um imaginário. Revista USP, n. 13, p. 78-87, 1992.

SOUZA, R.F. Educação e civilização nas zonas pioneiras do Estado de São Paulo (1933 1945). Cadernos de História da Educação. vol. 14, n. 2, p. 439-460, 2015.

SOUZA, R.F. A militarização da infância: Expressões do nacionalismo na cultura brasileira. Cad. CEDES, vol.20 no.52 Campinas, p. 104 - 121, 2000.

SOUZA, R.F. Templos de civilização: A implantação da escola primária graduada no estado de São Paulo (1890-1910). São Paulo: Unesp, 1998. 